\title{
Allergy-related diseases in childhood and risk for abdominal pain-related functional gastrointestinal disorders at 16 years-a birth cohort study
}

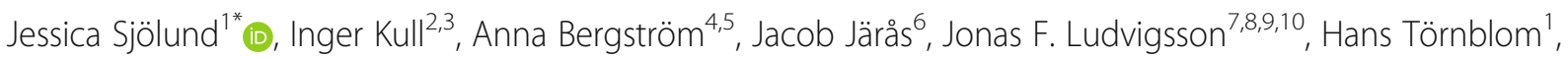
Magnus Simrén ${ }^{1,11}$ and Ola Olén ${ }^{3,6}$

\begin{abstract}
Background: Studies on allergy-related diseases in relation to abdominal pain-related functional gastrointestinal disorders (AP-FGIDs) in children are few and results are contradictory. We examined the associations between childhood allergy-related diseases and adolescent AP-FGIDs in general and irritable bowel syndrome (IBS) in particular.

Method: Prospective population-based birth cohort study of 4089 children born in Sweden 1994-1996. We analysed data from 2949 children with complete follow-up at 16 years (y) and no diagnosis of inflammatory bowel disease or coeliac disease at 12y or 16y. Asthma, rhinitis, eczema, and food hypersensitivity (FH) were assessed through questionnaires at 1-2y, 4y, 8y, 12y, and 16y. AP-FGIDs and IBS were assessed through questionnaires at 16y and defined according to the Rome III criteria. Associations between childhood allergy-related diseases and any APFGID and IBS and 16y respectively were examined using binomial generalized linear models with a log link function and described as relative risk with 95\% confidence intervals.

Results: The prevalence of any AP-FGID and IBS at $16 y$ were $12.0 \%$ and $6.0 \%$ respectively. Eczema at 1-2y, 4y, and $8 y$, and FH at $12 y$ and $16 y$ were associated with an increased risk for any AP-FGID at 16y. Asthma and FH at $12 y$ and 16y were associated with an increased risk for IBS at 16y. The relative risk for IBS at $16 y$ increased with increasing number of concurrent allergy-related diseases at 16y, but linear trend for relative risk was only borderline statistically significant $(P$ for trend $=0.05$ ).

Conclusions: This prospective population-based study demonstrated positive associations between childhood allergy-related diseases and adolescent AP-FGIDs, including IBS, implicating shared pathophysiology among these disorders.
\end{abstract}

Keywords: Allergy, Epidemiology, Functional abdominal pain, Irritable bowel syndrome, Paediatric gastroenterology

\footnotetext{
* Correspondence: jessica.sjolund@gu.se

'Department of Molecular and Clinical Medicine, Institute of Medicine,

Sahlgrenska Academy, University of Gothenburg, Box 428, 40530

Gothenburg, Sweden

Full list of author information is available at the end of the article
}

(c) The Author(s). 2021 Open Access This article is licensed under a Creative Commons Attribution 4.0 International License, which permits use, sharing, adaptation, distribution and reproduction in any medium or format, as long as you give appropriate credit to the original author(s) and the source, provide a link to the Creative Commons licence, and indicate if changes were made. The images or other third party material in this article are included in the article's Creative Commons licence, unless indicated otherwise in a credit line to the material. If material is not included in the article's Creative Commons licence and your intended use is not permitted by statutory regulation or exceeds the permitted use, you will need to obtain permission directly from the copyright holder. To view a copy of this licence, visit http://creativecommons.org/licenses/by/4.0/ The Creative Commons Public Domain Dedication waiver (http://creativecommons.org/publicdomain/zero/1.0/) applies to the data made available in this article, unless otherwise stated in a credit line to the data. 


\section{Background}

Childhood abdominal pain-related functional gastrointestinal disorders (AP-FGIDs) are common, affecting 13-25\% of children worldwide [1,2], and have major implications for affected individuals, their families, and society [3]. These disorders are diagnosed using diagnostic criteria, the most recent being the Rome IV criteria, as there are no biological markers or objective clinical findings defining these disorders $[4,5]$. One of the most common AP-FGIDs is irritable bowel syndrome (IBS), a disorder characterized by abdominal pain and altered bowel habits [2].

The pathophysiology of AP-FGIDs is not fully understood, but thought to be multifactorial involving complex gut-brain interactions [6]. Proposed pathophysiological mechanisms include low-grade inflammation and immune dysfunction [6], and the relevance of these are supported by clinical observations such as onset of IBS following an episode of infectious gastroenteritis [7], and IBS-like symptoms in a substantial proportion of patients with inflammatory bowel disease (IBD) and coeliac disease (in remission) [8]. Furthermore, both child and adult studies have shown increased infiltration and activation of immune cells such as mast cells and eosinophils in some patients with IBS [9-11] and functional dyspepsia (FD) [12-14].

Allergy-related diseases have been linked to adult APFGIDs [15-18]. We have previously shown that allergyrelated diseases are positively associated with recurrent functional abdominal pain in pre-adolescents [19]. While several others have explored the associations between asthma [16, 17, 20-25], allergic rhinitis [24, 25], and eczema [24-26] and paediatric AP-FGIDs, many have failed to take temporality into account (cross-sectional studies [20-24]), and of the four studies reporting long-term follow-up [16, 17, 25, 26], none used the Rome III [4] or IV [5] criteria to define AP-FGIDs. Furthermore, it is well known that adults with AP-FGIDs often report postprandial symptom exacerbation [27, 28], and immunemediated reactions might explain part of this association $[29,30]$. Food hypersensitivity (FH), here used as a general term for food-induced symptoms, is commonly reported also in paediatric AP-FGIDs [31-34], but longitudinal population-based studies regarding $\mathrm{FH}$ and paediatric APFGIDs defined by the Rome criteria are lacking.

Therefore, we aimed to, in a large prospective population-based birth cohort, test the hypothesis that childhood asthma, rhinitis, eczema, and FH are associated with an increased risk for adolescent Rome IIIdefined AP-FGIDs in general and IBS in particular.

\section{Methods}

\section{Participants}

We collected data from the BAMSE (Swedish abbreviation for Children, Allergy, Milieau, Stockholm, Epidemiology) study, a prospective population-based birth cohort study of 4089 children born in Sweden from 1994 through 1996 [35]. In BAMSE, parents reported baseline characteristics when their child was 2 months old, allergic symptoms and adverse reactions to food(s) in their child at 1, 2, 4, 8, 12, and 16 years (y), and physiciandiagnosed IBD and coeliac disease in their child at $12 y$ and 16y. Children self-reported gastrointestinal symptoms at $16 y$.

The current study was restricted to children who had answered the questions on gastrointestinal symptoms, at the 16y follow-up. We excluded children with IBD and coeliac disease at 12y and/or 16y. To avoid introducing selection bias, we did not exclude children with a missing report on these diseases, as the proportion of missing reports in the BAMSE cohort exceeds the expected age-specific prevalence of these diagnoses [36].

\section{Allergy-related diseases}

All allergy-related variables were based on parental reports. Detailed age-specific definitions of asthma, rhinitis, eczema, and FH are provided in this article's additional files (Additional file 1). We assessed both agespecific and overall (any report from 1y through 16y) prevalence. The number of concurrent allergy-related diseases at 16y was used as a proxy for allergy burden at $16 y$. Missing data on an allergy-related variable was considered a negative report if the parent(s) had participated at the follow-up questionnaire in question.

\section{AP-FGIDs}

At 16y, children answered questions based on the Questionnaire on Paediatric Gastrointestinal Symptoms-Rome III version [4] (Additional file 2). Answers were scored according to the paediatric Rome III criteria [4] for IBS, FD, and functional abdominal pain (FAP). Children who fulfilled the criteria for $\geq 1$ of these disorders were classified as having any AP-FGID.

\section{Statistics}

Statistical analyses were performed using STATA Statistical Software (STATA/SE 13.1; StataCorp LP, College Station, TX, USA). All variables were categorical. Prevalence was expressed as percentage of the number of observations available. Baseline characteristics of study participants were compared to the original BAMSE cohort by computing 95\% confidence intervals (CI) for study participants and adjusting for finite population sampling [37]. 95\% CI not including the prevalence in the original BAMSE cohort were considered statistically significant. Baseline characteristics and prevalence of allergy-related diseases in children with any AP-FGID and IBS respectively were compared to children with no AP-FGID using Pearson's chi-squared test, and $P<0.05$ (two-sided) was considered statistically significant. 
Age-specific and overall associations between childhood allergy-related diseases and any AP-FGID and IBS at $16 y$ respectively were examined using binomial generalized linear models (GLM) with a log link function and described as relative risk (RR) with 95\% CI. Children with no AP-FGID were used as the reference group in all analyses. Models were adjusted for sex, based on its putative role as a risk factor for AP-FGIDs and IBS [1]. All tests were two-sided, 95\% CI for RRs not including 1.0 were considered statistically significant, and missing observations were excluded from the analyses. Trend tests of RRs were performed to assess the association between allergy burden at 16y and any AP-FGID and IBS at $16 y$ respectively, and $P<0.05$ (two-sided) was considered statistically significant.

\section{Results}

\section{Participants}

We included 2949 children (Fig. 1). Compared to the original BAMSE cohort, children in the study population were more often the firstborn, exclusively breastfed > 4 months, and of higher socioeconomic status but fewer had a mother who smoked during pregnancy. Absolute differences between study participants and the original BAMSE cohort were however small (Additional file 3).

The prevalence of any AP-FGID and IBS at 16y was $12.0 \%$ and $6.0 \%$ respectively (Fig. 1 ). With the exception that any AP-FGID and IBS at 16y were more prevalent in girls, baseline characteristics did not vary with APFGID status (Table 1).

\section{Asthma}

Children with any AP-FGID at 16y more often had concurrent asthma (Fig. 2). In crude GLM, asthma at 16y was positively associated with any AP-FGID at 16y, but this did not remain statistically significant in sexadjusted models (Additional file 4).

Children with IBS at $16 y$ more often had asthma at $12 \mathrm{y}$ and $16 y$ (Fig. 2). In sex-adjusted GLM, overall (any report from 1y through 16y) asthma was positively associated with IBS at 16y (RR 1.4; 95\% CI 1.0-

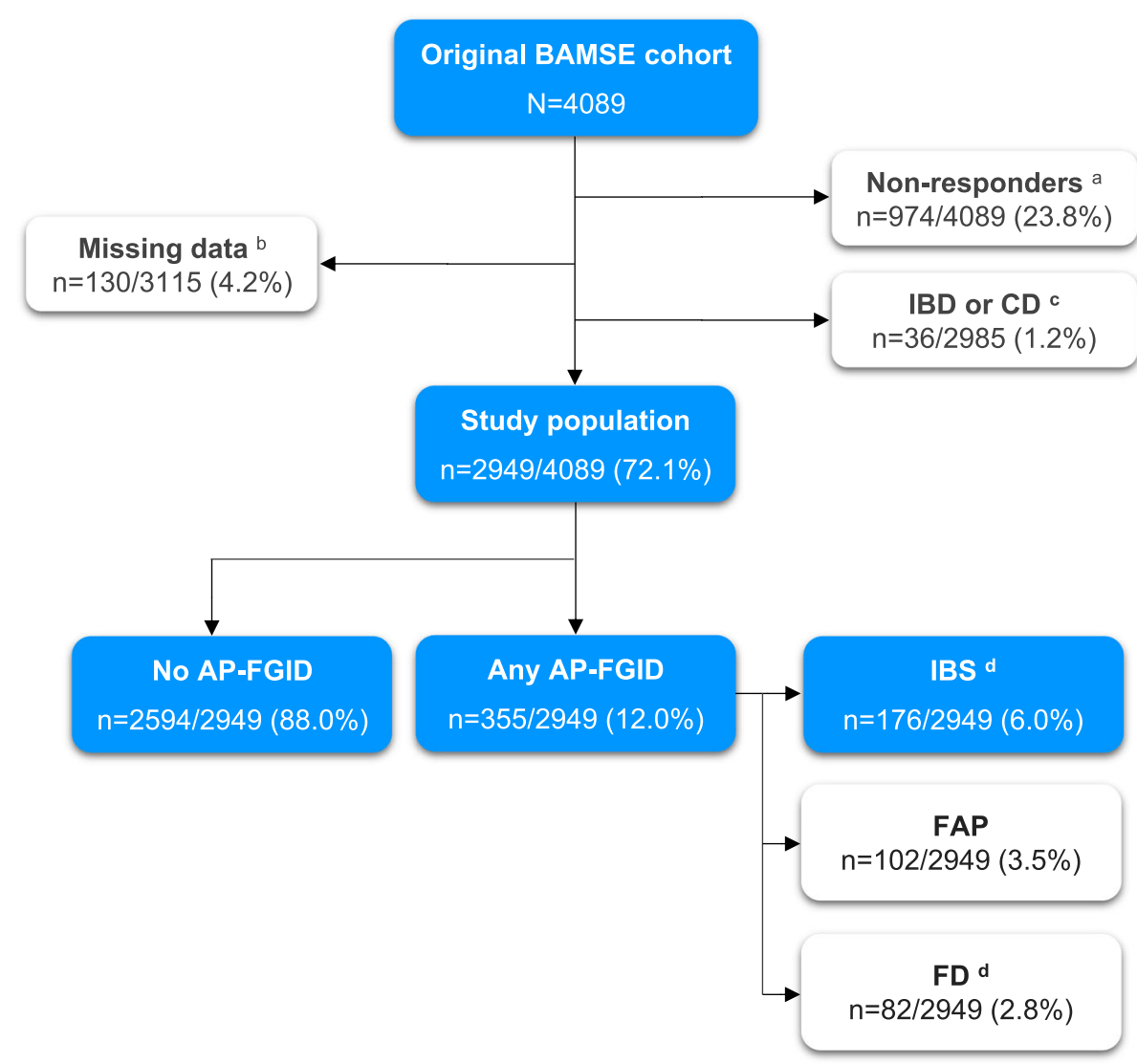

Fig. 1 Flow chart. Superscript lowercase letter "a" indicates children who did not participate in the 16y follow-up child questionnaire. Superscript lowercase letter "b" indicates missing data on gastrointestinal symptoms at the 16y follow-up child questionnaire. Superscript lowercase letter " $c$ " indicates at age $12 y$ and/or 16y. Superscript lowercase letter " $d$ " indicates five $(n=5)$ children had overlapping IBS and FD and are included in both the IBS and the FD category in the figure. AP-FGID, abdominal-pain related functional gastrointestinal disorder; CD, coeliac disease; FAP, functional abdominal pain; FD, functional dyspepsia; IBD, inflammatory bowel disease; IBS, irritable bowel syndrome; N, number; $y$, years 
Table 1 Comparison of baseline characteristics between children with vs. without any AP-FGID and IBS at 16y

\begin{tabular}{|c|c|c|c|c|c|}
\hline & \multirow{2}{*}{$\begin{array}{l}\text { No AP-FGID } \\
n=2594 \\
n / n(\%)\end{array}$} & \multicolumn{2}{|c|}{$\begin{array}{c}\text { Any AP-FGID } \\
n=355\end{array}$} & \multicolumn{2}{|c|}{$\begin{array}{c}\text { IBS } \\
n=176\end{array}$} \\
\hline & & $n / n(\%)$ & $p$ value $^{a}$ & $\mathrm{n} / \mathrm{n}(\%)$ & $p$ value $^{a}$ \\
\hline Male sex & $1347 / 2594(51.9)$ & 115/355 (32.4) & $<0.001$ & $64 / 176(36.4)$ & $<0.001$ \\
\hline Premature birth (<37 weeks) & 146/2594 (5.6) & 19/355 (5.4) & 0.83 & 10/176 (5.7) & 0.98 \\
\hline Maternal age $\leq 25$ years & 184/2593 (7.1) & $33 / 355(9.3)$ & 0.14 & 18/176 (10.2) & 0.12 \\
\hline Low birth weight < $2600 \mathrm{~g}$ & $123 / 2568(4.8)$ & $17 / 353(4.8)$ & 0.98 & $7 / 174(4.0)$ & 0.65 \\
\hline Exclusive breastfeeding $\geq 4$ months & $2041 / 2538(80.4)$ & 278/347 (80.1) & 0.89 & 133/170 (78.2) & 0.49 \\
\hline Older siblings & $1219 / 2594(47.0)$ & 165/355 (46.5) & 0.86 & 83/176 (47.2) & 0.97 \\
\hline Second hand smoke ${ }^{b}$ & $517 / 2578(20.1)$ & $75 / 353(21.2)$ & 0.60 & $42 / 175(24.0)$ & 0.21 \\
\hline Maternal smoking during pregnancy ${ }^{c}$ & $317 / 2593(12.2)$ & $42 / 355(11.8)$ & 0.83 & $17 / 176(9.7)$ & 0.31 \\
\hline \multicolumn{6}{|l|}{ Socioeconomic status of the household } \\
\hline Blue/lower white-collar worker, other ${ }^{d}$ & $780 / 2584(30.2)$ & 124/355 (34.9) & & $61 / 176(34.7)$ & \\
\hline Medium white-collar worker ${ }^{e}$ & $760 / 2548(29.4)$ & 105/355 (29.6) & 0.12 & $54 / 176(30.7)$ & 0.28 \\
\hline Higher white-collar worker (at least one parent) ${ }^{f}$ & $1044 / 2548(40.4)$ & $126 / 355(35.5)$ & & $61 / 176(34.7)$ & \\
\hline At least one parent has a university/college degree & $1453 / 2572(56.5)$ & $180 / 352(51.1)$ & 0.06 & $90 / 174(51.7)$ & 0.22 \\
\hline
\end{tabular}

Pearson's chi-squared test. Statistically significant differences (between children with no AP-FGID at 16 years vs. children with any AP-FGID or IBS at 16 years respectively) are shown in bold text

${ }^{\mathrm{b}}$ Any parent smoked $\geq 1$ cigarette/day at the time of the baseline questionnaire

${ }^{c}$ Mother smoked $\geq 1$ cigarette/day during pregnancy

'Blue/lower white collar worker include jobs with a normal requirement of $\leq 3$ years of education after 9 years of elementary school; other includes students,

housewife/man, person on disability pension, and unemployed

enclude jobs with a normal requirement of $\geq 3$ but $\leq 6$ years of education after 9 years of elementary schoo

IInclude jobs with a normal requirement of $\geq 6$ years of education after 9 years of elementary school

Abbreviations: AP-FGID, abdominal pain-related functional gastrointestinal disorder; IBS, irritable bowel syndrome; N, number
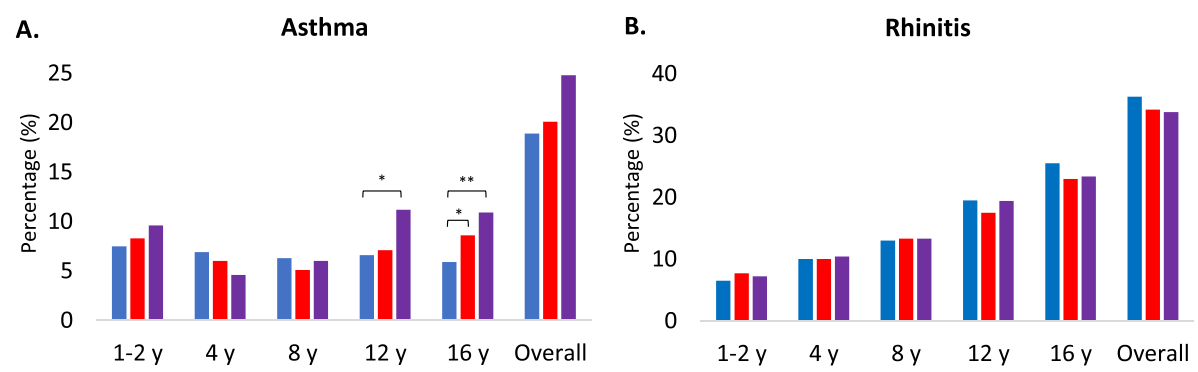

C.

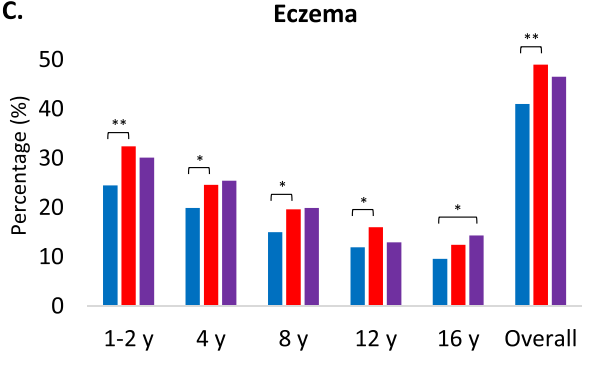

D.

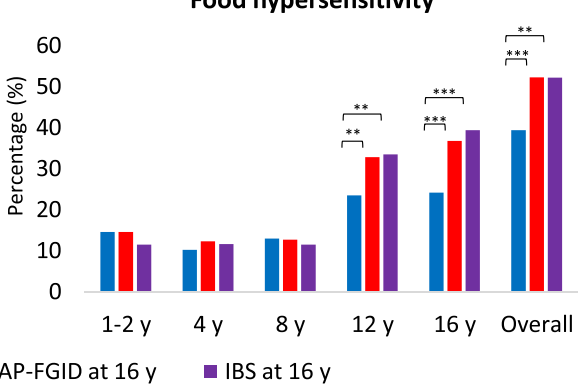

Fig. 2 Prevalence of childhood a asthma, $\mathbf{b}$ rhinitis, c eczema, and $\mathbf{d}$ food hypersensitivity. Age-specific and overall (any report from $1 \mathrm{y}$ through 16y) prevalence, stratified for children with no AP-FGID, any AP-FGID, and IBS at age 16y respectively. ${ }^{*} P<0.05 .{ }^{* *} P<0.01 .{ }^{* *} P<0.001$. AP-FGID, abdominal-pain related functional gastrointestinal disorder; IBS, irritable bowel syndrome; $y$, years 
2.1), with age-specific associations for asthma at $12 \mathrm{y}$ (RR 1.8; 95\% CI 1.2-2.9) and 16y (RR 1.8; 95\% CI 1.2-2.8) (Fig. 3).

\section{Rhinitis}

The prevalence of rhinitis did not vary with AP-FGID status at 16y (Fig. 2). In crude and sex-adjusted GLM, rhinitis was not associated with any AP-FGID or IBS at $16 y$ (Fig. 3).

\section{Eczema}

Children with any AP-FGID at 16y more often had eczema at $1-2 y, 4 y, 8 y$, and $12 y$ (Fig. 2). In sex-adjusted
GLM, overall eczema was positively associated with any AP-FGID at 16y (RR 1.3; 95\% CI 1.1-1.6), with agespecific associations for eczema at 1-2y (RR 1.4; 95\% CI 1.1-1.7), 4y (RR 1.3; 95\% CI 1.0-1.6), and 8y (RR 1.2; 95\% CI 1.0-1.6) (Fig. 3).

Children with IBS at 16y more often had concurrent eczema (Fig. 2). In sex-adjusted GLM, the RR for IBS at 16y was numerically increased in children with eczema at $1-2 y, 4 y$, and $8 y$, but this was not statistically significant (Fig. 3). In crude GLM, concurrent eczema was positively associated with IBS at 16y, but this did not remain statistically significant in sexadjusted models (Additional file 4).
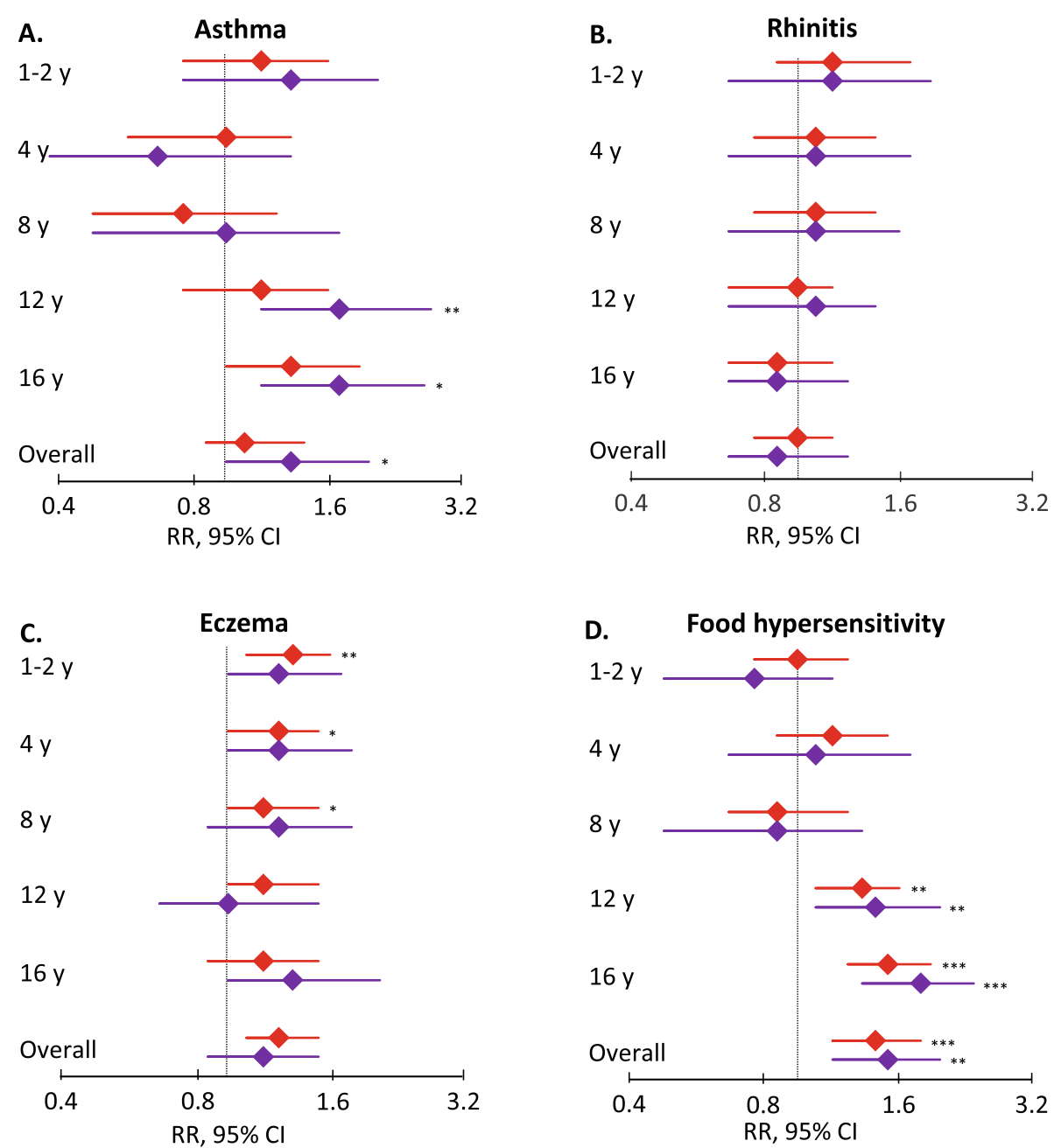

Fig. 3 Associations between childhood a asthma, b rhinitis, c eczema, d food hypersensitivity, and any AP-FGID and IBS at 16y. Age-specific and overall (any report from 1y through 16y) associations between allergy-related diseases during childhood and any AP-FGID and IBS at 16 years respectively. Associations were assessed in a binomial generalized linear model with a log link function and adjusted for sex. Children with no APFGID at age $16 y$ were used as the reference group in all analyses. ${ }^{*} P<0.05$. ${ }^{*} P<0.01$. ${ }^{* *} P<0.001$. AP-FGID, abdominal pain-related functional gastrointestinal disorders; Cl, confidence interval; IBS, irritable bowel syndrome; RR, relative risk; $y$, years 
$\mathrm{FH}$

Children with any AP-FGID at 16y more often had FH at $12 \mathrm{y}$ and 16y (Fig. 2). In sex-adjusted GLM, overall FH was positively associated with any AP-FGID at 16y (RR 1.5; 95\% CI 1.2-1.9), with age-specific associations for $\mathrm{FH}$ at $12 \mathrm{y}$ (RR 1.4; 95\% CI 1.1-1.7) and 16y (1.6; 95\% CI 1.3-2.0) (Fig. 3).

Children with IBS at $16 y$ more often had FH at $12 \mathrm{y}$ and 16y (Fig. 2). In sex-adjusted GLM, overall FH was positively associated with IBS at 16y (RR $1.695 \%$ CI $1.2-2.1$ ), with age-specific associations for $\mathrm{FH}$ at $12 \mathrm{y}$ (RR 1.5; 95\% CI 1.1-2.1) and 16y (RR 1.9; 95\% CI 1.4-2.5) (Fig. 3).

\section{Allergy burden}

An increasing number of concurrent allergy-related diseases at 16y did not affect the RR for any AP-FGID at 16y (Fig. 4). The RR for IBS at 16y increased with an increasing number of concurrent allergy-related diseases at $16 y$, but the linear trend for RR was only borderline statistically significant (Fig. 4).

\section{Discussion}

In this large prospective population-based birth cohort study, overall (any report from 1y through 16y) eczema and FH were positively associated with any Rome IIIdefined AP-FGID at 16y, with age-specific associations for eczema at $1-2 y, 4 y$, and $8 y$ and for $F H$ at $12 y$ and

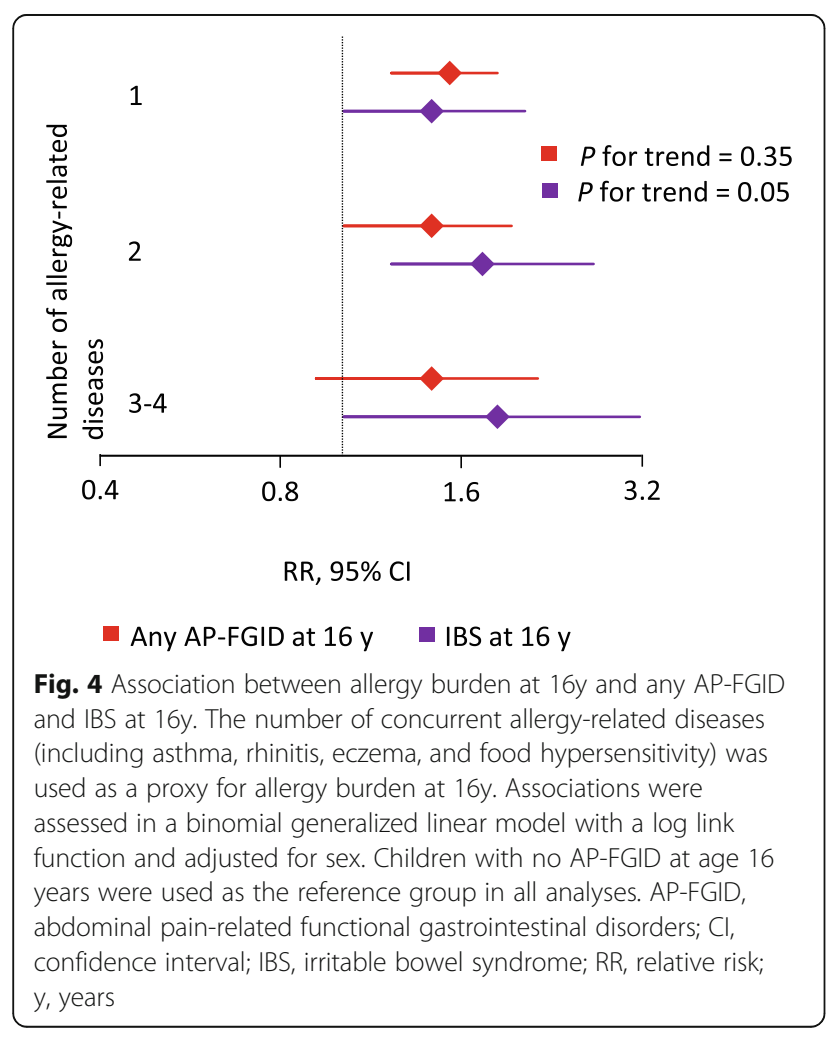

16y. Further, we found that overall asthma and overall FH were positively associated with Rome III-defined IBS at 16y, with age-specific associations for asthma and $\mathrm{FH}$ at $12 \mathrm{y}$ and 16y. Targeting immunological mechanisms present in both AP-FGIDs and allergy-related diseases might offer novel therapeutic modalities for AP-FGIDs.

We have previously demonstrated a link between recurrent functional abdominal pain at $12 \mathrm{y}$ and concurrent or earlier asthma [19]. When assessing Rome III-defined abdominal pain at 16y, early childhood asthma did not remain associated to AP-FGIDs, whereas asthma at $12 y$ and $16 y$ did. In accordance, the majority of the previous studies including children [16, 17, 20-25] report a high prevalence and/or increased risk for abdominal pain of functional origin [20,22], AP-FGIDs [21, 23], and IBS $[16,17,25]$ when asthma was present. Most studies, however, were cross-sectional [20-24] and of them only Kumari and Colman $[21,23]$ used the Rome III criteria to define AP-FGIDs (none used the Rome IV criteria). Kumari et al. showed an increased risk for concurrent FD, FAP, and abdominal migraine, but not IBS in asthmatics in a population-based sample of 1101 children in Sri Lanka [21]. This contrasts with our study where asthma was positively associated with IBS, but not APFGIDs in general. The discrepancy could be related to differences in sample size, age of assessment (we assessed AP-FGIDs at a later age), and geographical differences of asthma and IBS (we reported a higher prevalence of IBS and lower prevalence of asthma). Colman et al. reported a high prevalence of AP-FGIDs in paediatric patients with persistent asthma and poorer asthma control in patients with AP-FGIDs, but made no attempt to assess the risk for AP-FGIDs in asthmatics relative to non-asthmatics [23]. Of the three longitudinal studies identified, all reported a positive association between asthma and subsequent IBS. Cole and Huerta, however, included both children and adults and made no attempt to report specific paediatric associations $[16,17]$. Tan et al. used ICD-codes to identify cases and their results might therefore not be generalizable to the general population [25].

In our previous study in this cohort, we showed positive associations between recurrent functional abdominal and concurrent rhinitis and eczema at 12y [19]. When assessing Rome III-defined abdominal pain at 16y, rhinitis was not associated with AP-FGIDs. We were only able to identify two other studies assessing rhinitis in relation to paediatric AP-FGIDs, with one study reporting an increased risk for subsequent IBS in children with rhinitis [25] and one reporting no association between rhinitis and concurrent IBS [24]. Both studies were however based on selected samples, assessed IBS in younger children, and used outdated or non-accepted criteria to define IBS. The same studies report similar and 
contradictory associations between eczema and IBS. A third study, report an increased risk for subsequent IBS in children with eczema in Taiwan [26]. While we similarly found positive associations between childhood eczema and adolescent AP-FGIDs in general, we did not find statistically significant associations with adolescent IBS. This discrepancy could be due to the different types of samples (their sample was patient based) and criteria to define IBS (they used ICD-codes under the Rome II era). It is also possible that low statistical power prevented us from detecting statistically significant associations between eczema and IBS.

Compared to healthy peers, adolescents with APFGIDs in our study had a higher prevalence of $\mathrm{FH}$ at $12 \mathrm{y}$ and $16 \mathrm{y}$. This is consistent with previous studies, although our prevalence of $\mathrm{FH}$ was lower than what has been reported by others in similar age groups [31-33]. Previous studies, however, were conducted on selected patient samples. Further, they were designed to assess FH and/or dietary interventions, which might have caused selection of children with more food-related symptoms. Longitudinal studies of $\mathrm{FH}$ and the risk for subsequent AP-FGIDs are limited. Saps et al. found cow's milk allergy during the first year of life to predispose for pre-adolescent AP-FGIDs [34], but studies assessing $\mathrm{FH}$ in general (as opposed to a single food item) are lacking.

We did not assess allergy-related diseases and discrete AP-FGIDs, but the differences in results for AP-FGIDs vs. IBS suggest that associations may differ between subtypes. Further, although $P$ for trend was not statistically significant, the number of concurrent allergy-related diseases increased the RR for IBS, while the RR for any APFGID stayed unaffected. This might suggest that allergy is more connected to IBS than to the other AP-FGID subtypes. Except for the study by Kumari et al. discussed above [21], we found no additional studies that have addressed this issue in children. Hence, it would be of clinical and potentially mechanistic interest to stratify for different AP-FGID subtypes when assessing associations to allergy-related diseases in future studies.

Possible explanations of our results include shared pathophysiological mechanisms between asthma, eczema, and FH and adolescent AP-FGIDs. Mast cells and eosinophils, key effector cells in allergy, have been implicated in youth AP-FGIDs. Paediatric IBS has been associated to increased number of mucosal mast cells and mast cells in close proximity to mucosal nerves, which also seem to correlate with pain intensity and frequency $[9,11]$. Furthermore, an adult study found that allergic IBS patients had more severe IBS symptoms and higher numbers of mucosal mast cells [38], and others found mucosal immune reactions in IBS patients after mucosal exposure to food antigens $[29,30]$. In addition, both mast cells and eosinophils have been implicated in paediatric FD $[12,14]$. On the other hand, we did not find any associations between AP-FGIDs and rhinitis, a condition also associated with mast cells and eosinophils. It would be interesting for future studies to investigate mucosal immune activation in individuals with AP-FGIDs and different allergy-related diseases to better understand this overlap.

Further, it is plausible that shared genetic and environmental risk factors may have contributed to our results. Also, allergic children may have increased awareness of bodily symptoms, therefore reporting more symptoms in general. However, at least in adults, the associations between asthma and gastrointestinal symptoms remained when using a control group with other chronic diseases in addition to healthy controls [39]. Furthermore, allergic children report lower quality of life and higher levels of anxiety and depression [40]. It is possible that these effects and not the allergy in itself influence the progress of AP-FGIDs, as anxiety, stress, and symptom awareness are highly implicated internal triggers in the development and/or maintenance of AP-FGIDs [41, 42]. Studies in adults have shown that controlling for mood disorders partly explained the associations between allergy-related diseases and AP-FGIDs [15]. Future studies would need to assess if this also applies to children, as our dataset unfortunately did not allow us to adjust for this.

The most apparent strengths of this study include the population-based design, the large sample size, the evaluation of several allergy-related diseases, the prospective and repeated assessment of allergy-related diseases, and the use of the Rome III criteria [4] to define AP-FGIDs.

As BAMSE was designed to study allergy-related diseases, it is possible that families with allergic children would be more inclined to participate. However, the prevalence of allergy-related diseases during the first years of life was equal in those entering the study and those remaining at $16 y$, speaking against any major selection bias of more allergic children in our study.

Our definitions of asthma, rhinitis, and eczema have been validated and are highly specific $(87-100 \%)$ [43, 44]. Further, the prevalence of rhinitis and eczema in our study are in accordance with other population-based studies of similar age groups [45-47]. Although our prevalence of asthma is similar to that reported by some [48], it is lower than that reported by others [46, 49]. While this could be due to actual differences in the populations, we cannot rule out that our strict definition failed to identify all asthma cases.

Our definition of FH did not include a food challenge or objective sensitization measurement (i.e. skin prick test or serum IgE). This is problematic as there is a wellknown discrepancy between perceived and confirmed 
$\mathrm{FH}$ in the population [50]. However, also, when using objective measurements to assess $\mathrm{FH}$, there is great diversity in the reported prevalence, highlighting the difficulties with diagnosing $\mathrm{FH}$ [50]. In addition, it has been suggested that the immune response related to food antigens in individuals with IBS might not be IgE-driven [29] or limited to local mucosal IgE reactions [30] and thus not detectable with classical food allergy tests such as serum IgE. Furthermore, symptoms in non-classical food allergy may be delayed, which also makes provocation tests problematic [29]. It is likely that the reported $\mathrm{FH}$ in our study is caused by a mix of nonimmunological and immunological mechanisms. However, until the mechanisms behind FH in AP-FGIDs have been better elucidated, we believe there is relevance in data on perceived $\mathrm{FH}$ with regards to the epidemiology of FH in relation to AP-FGIDs.

While we used the Rome III criteria to define APFGIDs, case ascertainment did not include a medical evaluation. We did however exclude children with IBD and coeliac disease, and we did previously show that the prevalence of these diagnoses in this cohort are within the expected range [36]. Our dataset prevented us from considering additional organic causes of abdominal pain, but many of these have been shown to be rare in Scandinavian children [51, 52]. Further, we previously reported a clinical follow-up of IBS cases in this cohort, demonstrating a high internal validity of the IBS-classification [36]. Also, the prevalence of AP-FGIDs in our study corresponds well with the reported prevalence of Rome IIIdefined AP-FGIDs in similar age groups [53, 54]. The reported prevalence of FD increased significantly with the transition from Rome III to Rome IV and the introduction of the diagnostic subgroups epigastric pain syndrome and postprandial distress syndrome (PDS), as FD in the case of PDS now can be diagnosed in the absence of abdominal pain $[2,55]$. The prevalence of $F D$ and FD-cases experiencing PDS-symptoms in our study would thus likely be higher using the Rome IV criteria. Although we do not report on specific associations between allergies and FD, FD is included in any AP-FGID in our study. Therefore, we cannot rule out that the usage of the Rome IV criteria would affect the associations seen between allergies and any Rome III AP-FGIDs in our study. This might particularly be relevant if the association between allergy and AP-FGIDs is caused by shared pathophysiological mechanisms, as an increase in antral mast cells and eosinophils has been associated with PDS-symptoms such as early satiety but not with epigastric/abdominal pain in children with $\mathrm{FD}[56,57]$.

Unfortunately, we did not know the onset of APFGIDs and IBS. Thus, we cannot determine the temporal relationship between allergy-related diseases and AP-FGIDs and IBS in our study. This applies in particular to the associations seen with pre-adolescent asthma and $\mathrm{FH}$, while we find it plausible to assume that eczema likely preceded the development of APFGIDs.

\section{Conclusions}

In conclusion, we report that eczema and FH are positively associated with adolescent AP-FGIDs in general, and asthma and FH are positively associated with adolescent IBS. Clinicians faced with these patients should be aware of the co-morbidity between allergy-related diseases and AP-FGIDs. Our results further support the potential role of low-grade inflammation and immune dysregulation in the pathogenesis of paediatric APFGIDs.

\section{Abbreviations}

AP-FGID: Abdominal-pain related functional gastrointestinal disorders; BAMSE: Swedish abbreviation for Children, Allergy, Milieau, Stockholm, Epidemiology; Cl: Confidence interval; FAP: Functional abdominal pain; FD: Functional dyspepsia; FH: Food hypersensitivity; GLM: Generalized linear model; IBD: Inflammatory bowel disease; IBS: Irritable bowel syndrome; RR: Relative risk; Y: Year

\section{Supplementary Information}

The online version contains supplementary material available at https://doi. org/10.1186/s12916-021-02069-3.

Additional file 1. Age-specific definitions of asthma, rhinitis, eczema, and food hypersensitivity and questionnaire questions used for classification of food hypersensitivity.

Additional file 2. Questionnaire questions and answer options in the 16y child-questionnaire used to classify Rome III abdominal pain-related functional gastrointestinal disorders at $16 y$.

Additional file $\mathbf{3}$ Comparison of baseline characteristics between the entire original BAMSE cohort and study participants. ${ }^{a}$ Confidence intervals were adjusted for finite population sampling. Statistically significant differences between the entire BAMSE cohort and study participants are shown in bold text. ${ }^{b}$ Any parent smoked $\geq 1$ cigarette/ day at the time of the baseline questionnaire. ${ }^{c}$ Mother smoked $\geq 1$ cigarette/day during pregnancy. ${ }^{d}$ Blue/lower white-collar worker include jobs with a normal requirement of $\leq 3 y$ of education after 9y of elementary school; other includes students, housewife/man, person on disability pension, and un-employed. ${ }^{e}$ Includes jobs with a normal requirement of $\geq 3 y$ but $\leq 6 y$ of education after $9 y$ of elementary school. ${ }^{f}$ Includes jobs with a normal requirement of $\geq 6 y$ of education after $9 y$ of elementary school. Abbreviations: AP-FGID, abdominal pain-related functional gastrointestinal disorder; $\mathrm{Cl}$, confidence interval; $\mathrm{N}$, number; $Y$, years.

Additional file 4 Associations between childhood allergy-related diseases and any AP-FGID and IBS at 16y. ${ }^{a}$ Cases refers to children with any AP-FGID/IBS at 16y. Non-cases refers to children with no AP-FGID at 16y. The column shows the number of cases and non-cases exposed (yes) vs. unexposed (no) to asthma/rhinitis/eczema/food hypersensitivity at different ages. ${ }^{b}$ Pearson's chi-squared test. Statistically significant differences of the AR of developing AP-FGID/IBS at 16y between children exposed and children unexposed to asthma/rhinitis/eczema/food hypersensitivity are shown in bold text. ${ }^{c}$ Age-specific and overall (any report from 1y through 16y) associations assessed in a binomial generalized linear model with a log link function. Children with no AP-FGID at 16y were used as the reference group in all analyses. Statistically significant associations are marked in bold text. Abbreviations: AP-FGID, abdominal pain-related functional gastrointestinal disorder; $A R$, absolute risk; aRR, adjusted relative risk; $\mathrm{Cl}$, confidence interval; IBS, irritable bowel syndrome; $\mathrm{N}$, number; $\mathrm{RR}$, relative risk; $Y$, years. 


\section{Acknowledgements}

We thank all the participants in the BAMSE study as well as all the staff involved, especially Eva Hallner and Sara Nilsson.

\section{Authors' contributions}

$J S, I K, A B, H T, M S$, and $O O$ developed the study concept and design. IK, $A B$, and $\mathrm{OO}$ participated in data acquisition. JS and JJ performed the statistical analysis. JS, IK, AB, JJ, HT, MS, and $O O$ interpreted the data. JS, HT, MS, and $\mathrm{OO}$ drafted the manuscript. JS, IK, AB, JFL, HT, MS, and OO critically revised the work for important intellectual content. All authors read and approved the final version of the manuscript.

\section{Funding}

This study was supported by the Swedish Research Council (grants 201802566), AFA Insurance (190087), Bengt Ihre Foundation, and by the Faculty of Medicine, University of Gothenburg. The BAMSE birth cohort was supported by the Swedish Research Council (2017-02529, 2018-02524),

Stockholm County Council, the Swedish Heart and Lung Foundation (20180579), the Swedish Research Council for Health, Working Life and Welfare (2010-00451, 2017-00526), the Swedish Asthma and Allergy Foundation (F2019-0009), and the European Commission's Seventh Framework 29 Program MeDALL (grant 261357). The funding organizations had no role in the design and conduct of the study; collection, management, analysis, and interpretation of the data; preparation, review, or approval of the manuscript; and decision to submit the manuscript for publication. Open Access funding provided by University of Gothenburg.

\section{Availability of data and materials}

The datasets generated and/or analysed during the current study are not publicly available due to the dataset containing sensitive personal data but are available from the corresponding author on reasonable request and with permission of Karolinska Institutet.

\section{Declarations}

\section{Ethics approval and consent to participate}

Ethical permission was obtained by the Regional Ethical Review Board, Karolinska Institutet, Stockholm (DNR 93-189; 98-175; 01-478; 02-420; 2007/ $1634-31 ; 2010 / 1474-31 / 3)$. Written informed consent was received from the parents/guardians on behalf of their children.

\section{Consent for publication}

Not applicable.

\section{Competing interests}

MS received unrestricted research grants from Danone Nutricia Research, and Glycom, and served as a Consultant/Advisory Board member for Danone Nutricia Research, Ironwood, Menarini, Biocodex, Genetic Analysis AS, Glycom, Arena and Adnovate, and as a speaker for Tillotts, Menarini, KyowaKirin, Takeda, Shire, Biocodex, Alimentary Health, AlfaSigma, and Falk Foundation. HT has served as Consultant/Advisory Board member for Allergan and as a speaker for Tillotts, Takeda, and Shire. JFL coordinates a study on behalf of the Swedish IBD quality register (SWIBREG). This study has received funding from Janssen corporation.

The other authors have no relevant conflicts of interests to disclose.

\section{Author details}

'Department of Molecular and Clinical Medicine, Institute of Medicine, Sahlgrenska Academy, University of Gothenburg, Box 428, 40530 Gothenburg, Sweden. '2Department of Clinical Science and Education, Södersjukhuset, Karolinska Institutet, Stockholm, Sweden. 'Sachs' Children's Hospital, Stockholm, Sweden. ${ }^{4}$ Institute of Environmental Medicine, Karolinska Institutet, Stockholm, Sweden. ${ }^{5}$ Centre for Occupational and Environmental Medicine, Stockholm County Council, Stockholm, Sweden. ${ }^{6}$ Division of Clinical Epidemiology, Department of Medicine Solna, Karolinska Institutet, Stockholm, Sweden. 'Department of Medical Epidemiology and Biostatistics, Karolinska Institutet, Stockholm, Sweden. ${ }^{8}$ Department of Paediatrics, Örebro University Hospital, Örebro, Sweden. ${ }^{9}$ Division of Epidemiology and Public Health, School of Medicine, University of Nottingham, Nottingham, UK. ${ }^{10}$ Department of Medicine, Columbia University College of Physicians and Surgeons, New York, NY, USA. ${ }^{11}$ Centre for Functional GI and Motility Disorders, University of North Carolina, Chapel Hill, NC, USA.

Received: 14 May 2021 Accepted: 21 July 2021

Published online: 16 September 2021

\section{References}

1. Korterink JJ, Diederen K, Benninga MA, Tabbers MM. Epidemiology of pediatric functional abdominal pain disorders: a meta-analysis. PLoS One. 2015;10(5):e0126982. https://doi.org/10.1371/journal.pone.0126982.

2. Robin SG, Keller C, Zwiener R, Hyman PE, Nurko S, Saps M, et al. Prevalence of pediatric functional gastrointestinal disorders utilizing the Rome IV criteria. J Pediatr. 2018;195:134-9. https://doi.org/10.1016/j.jpeds.2017.12.012.

3. Varni JW, Bendo CB, Nurko S, Shulman RJ, Self MM, Franciosi JP, et al. Health-related quality of life in pediatric patients with functional and organic gastrointestinal diseases. J Pediatr. 2015;166(1):85-90. https://doi. org/10.1016/j.jpeds.2014.08.022.

4. Rasquin A, Di Lorenzo C, Forbes D, Guiraldes E, Hyams JS, Staiano A, et al. Childhood functional gastrointestinal disorders: child/adolescent. Gastroenterology. 2006;130(5):1527-37. https://doi.org/10.1053/j.gastro.2005. 08.063 .

5. Hyams JS, Di Lorenzo C, Saps M, Shulman RJ, Staiano A, van Tilburg M. Functional disorders: children and adolescents. Gastroenterology. 2016; 150(6):1456-68.e2.

6. Thapar N, Benninga MA, Crowell MD, Di Lorenzo C, Mack I, Nurko S, et al. Paediatric functional abdominal pain disorders. Nat Rev Dis Primers. 2020; 6(1):89. https://doi.org/10.1038/s41572-020-00222-5.

7. Schwille-Kiuntke J, Mazurak N, Enck P. Systematic review with meta-analysis: post-infectious irritable bowel syndrome after travellers' diarrhoea. Aliment Pharmacol Ther. 2015;41(11):1029-37. https://doi.org/10.1111/apt.13199.

8. Aziz I, Simren M. The overlap between irritable bowel syndrome and organic gastrointestinal diseases. Lancet Gastroenterol Hepatol. 2021;6(2): 139-48. https://doi.org/10.1016/S2468-1253(20)30212-0.

9. Singh M, Singh V, Schurman JV, Colombo JM, Friesen CA. The relationship between mucosal inflammatory cells, specific symptoms, and psychological functioning in youth with irritable bowel syndrome. Sci Rep. 2020;10(1): 11988. https://doi.org/10.1038/s41598-020-68961-9.

10. Bashashati M, Moossavi S, Cremon C, Barbaro MR, Moraveji S, Talmon G, et al. Colonic immune cells in irritable bowel syndrome: a systematic review and meta-analysis. Neurogastroenterol Motil. 2018;30(e13192). https://doi. org/10.1111/nmo.13192.

11. Di Nardo G, Barbara G, Cucchiara S, Cremon C, Shulman RJ, Isoldi S, et al. Neuroimmune interactions at different intestinal sites are related to abdominal pain symptoms in children with IBS. Neurogastroenterol Motil. 2014;26(2):196-204. https://doi.org/10.1111/nmo.12250.

12. Friesen CA, Lin Z, Singh M, Singh V, Schurman JV, Burchell N, et al. Antral inflammatory cells, gastric emptying, and electrogastrography in pediatric functional dyspepsia. Dig Dis Sci. 2008:53(10):2634-40. https://doi.org/10.1 007/s10620-008-0207-0.

13. Wauters $L$, Ceulemans $M$, Frings $D$, Lambaerts $M$, Accarie $A$, Toth J, et al. Proton pump inhibitors reduce duodenal eosinophilia, mast cells, and permeability in patients with functional dyspepsia. Gastroenterology. 2020 https://doi.org/10.1053/j.gastro.2020.12.016.

14. Wauters L, Nightingale S, Talley NJ, Sulaiman B, Walker MM. Functional dyspepsia is associated with duodenal eosinophilia in an Australian paediatric cohort. Aliment Pharmacol Ther. 2017;45(10):1358-64. https://doi. org/10.1111/apt.14045.

15. Jones MP, Walker MM, Ford AC, Talley NJ. The overlap of atopy and functional gastrointestinal disorders among 23,471 patients in primary care. Aliment Pharmacol Ther. 2014;40(4):382-91. https://doi.org/10.1111/apt.12846.

16. Cole JA, Rothman K, Cabral HJ, Zhang Y, Farraye FA. Incidence of IBS in a cohort of people with asthma. Dig Dis Sci. 2007;52(2):329-35. https://doi. org/10.1007/s10620-006-9530-5.

17. Huerta C, Garcia Rodriguez LA, Wallander MA, Johansson S. Risk of irritable bowel syndrome among asthma patients. Pharmacoepidemiol Drug Saf. 2002;11(1):31-5. https://doi.org/10.1002/pds.666.

18. Shen TC, Lin CL, Wei CC, Chen CH, Tu CY, Hsia TC, et al. Bidirectional association between asthma and irritable bowel syndrome: two populationbased retrospective cohort studies. PLoS One. 2016;11(4):e0153911. https:// doi.org/10.1371/journal.pone.0153911. 
19. Olen O, Neuman A, Koopmann B, Ludvigsson JF, Ballardini N, Westman M, et al. Allergy-related diseases and recurrent abdominal pain during childhood - a birth cohort study. Aliment Pharmacol Ther. 2014;40(11-12): 1349-58. https://doi.org/10.1111/apt.12965.

20. Ronchetti R, Villa MP, Matricardi PM, La Grutta S, Barreto M, Pagani J, et al. Association of asthma with extra-respiratory symptoms in schoolchildren: two cross-sectional studies 6 years apart. Pediatr Allergy Immunol. 2002; 13(2):113-8. https://doi.org/10.1034/j.1399-3038.2002.01036.x.

21. Kumari MV, Devanarayana NM, Amarasiri L, Rajindrajith S. Association between functional abdominal pain disorders and asthma in adolescents: A cross-sectional study. World J Clin Cases. 2018;6(15):944-51. https://doi.org/1 0.12998/wjcc.v6.i15.944.

22. Peckham C, Butler N. A national study of asthma in childhood. J Epidemiol Community Health. 1978;32(2):79-85.

23. Colman RJ, Rosario NBS, Gutierrez Bonilla A, Benavidez Alvarez G, Benavidez Alvarez J, Uy VP, et al. Prevalence of functional GI disorders among pediatric patients with persistent asthma. J Dig Dis. 2018;19(9):522-8. https://doi.org/1 0.1111/1751-2980.12653.

24. Caffarelli C, Coscia A, Baldi F, Borghi A, Capra L, Cazzato S, et al. Characterization of irritable bowel syndrome and constipation in children with allergic diseases. Eur J Pediatr. 2007;166(12):1245-52. https://doi.org/1 0.1007/s00431-006-0410-y.

25. Tan TK, Chen AC, Lin CL, Shen TC, Li TC, Wei CC. Preschoolers with allergic diseases have an increased risk of irritable bowel syndrome when reaching school age. J Pediatr Gastroenterol Nutr. 2017;64(1):26-30. https://doi.org/1 0.1097/MPG.0000000000001219.

26. Tsai JD, Wang IC, Shen TC, Lin CL, Wei CC. A 8-year population-based cohort study of irritable bowel syndrome in childhood with history of atopic dermatitis. J Investig Med. 2018;66(4):755-61. https://doi.org/10.1136/ jim-2017-000631.

27. Bohn L, Storsrud S, Tornblom H, Bengtsson U, Simren M. Self-reported foodrelated gastrointestinal symptoms in IBS are common and associated with more severe symptoms and reduced quality of life. Am J Gastroenterol. 2013;108(5):634-41. https://doi.org/10.1038/ajg.2013.105.

28. Posserud I, Strid H, Storsrud S, Tornblom H, Svensson U, Tack J, et al. Symptom pattern following a meal challenge test in patients with irritable bowel syndrome and healthy controls. United European Gastroenterol J. 2013;1(5):358-67. https://doi.org/10.1177/2050640613501 817.

29. Fritscher-Ravens A, Pflaum T, Mosinger M, Ruchay Z, Rocken C, Milla PJ, et al. Many patients with irritable bowel syndrome have atypical food allergies not associated with immunoglobulin E. Gastroenterology. 2019; 157(1):109-18 e5. https://doi.org/10.1053/j.gastro.2019.03.046.

30. Aguilera-Lizarraga J, Florens MV, Viola MF, Jain P, Decraecker L, Appeltans I, et al. Local immune response to food antigens drives meal-induced abdominal pain. Nature. 2021;590(7844):151-6. https://doi.org/10.1038/s41 586-020-03118-2.

31. Chumpitazi BP, Weidler EM, Lu DY, Tsai CM, Shulman RJ. Self-perceived food intolerances are common and associated with clinical severity in childhood irritable bowel syndrome. J Acad Nutr Diet. 2016;116(9):1458-64. https://doi. org/10.1016/j.jand.2016.04.017.

32. Carlson MJ, Moore CE, Tsai CM, Shulman RJ, Chumpitazi BP. Child and parent perceived food-induced gastrointestinal symptoms and quality of life in children with functional gastrointestinal disorders. J Acad Nutr Diet. 2014; 114(3):403-13. https://doi.org/10.1016/j.jand.2013.10.013.

33. Reed-Knight B, Squires M, Chitkara DK, van Tilburg MA. Adolescents with irritable bowel syndrome report increased eating-associated symptoms, changes in dietary composition, and altered eating behaviors: a pilot comparison study to healthy adolescents. Neurogastroenterol Motil. 2016; 28(12):1915-20. https://doi.org/10.1111/nmo.12894.

34. Saps M, Lu P, Bonilla S. Cow's-milk allergy is a risk factor for the development of FGIDs in children. J Pediatr Gastroenterol Nutr. 2011;52(2): 166-9. https://doi.org/10.1097/MPG.0b013e3181e85b55.

35. Wickman M, Kull I, Pershagen G, Nordvall SL. The BAMSE project: presentation of a prospective longitudinal birth cohort study. Pediatr Allergy Immunol. 2002;13(s15):11-3. https://doi.org/10.1034/j.1399-303 8.13.s.15.10.x

36. Sjolund J, Uusijarvi A, Tornkvist NT, Kull I, Bergstrom A, Alm J, et al. Prevalence and progression of recurrent abdominal pain, from early childhood to adolescence. Clin Gastroenterol Hepatol. 2021;19(5):930-8 e8. https://doi.org/10.1016/j.cgh.2020.04.047.
37. Herringa SG, West BT, Berglund PA. Applied survey data analysis. Boca Raton: Taylor \& Francis; 2010. https://doi.org/10.1201/9781420080674.

38. Vivinus-Nebot M, Dainese R, Anty R, Saint-Paul MC, Nano JL, Gonthier N, et al. Combination of allergic factors can worsen diarrheic irritable bowel syndrome: role of barrier defects and mast cells. Am J Gastroenterol. 2012; 107(1):75-81. https://doi.org/10.1038/ajg.2011.315.

39. Powell N, Huntley B, Beech T, Knight W, Knight H, Corrigan CJ. Increased prevalence of gastrointestinal symptoms in patients with allergic disease. Postgrad Med J. 2007;83(977):182-6. https://doi.org/10.1136/pgmj.2006.04 9585.

40. Covaciu C, Bergstrom A, Lind T, Svartengren M, Kull I. Childhood allergies affect health-related quality of life. J Asthma. 2013;50(5):522-8. https://doi. org/10.3109/02770903.2013.789057.

41. Newton E, Schosheim A, Patel S, Chitkara DK, van Tilburg MAL. The role of psychological factors in pediatric functional abdominal pain disorders. Neurogastroenterol Motil. 2019;31(6):e13538. https://doi.org/10.1111/nmo.13 538.

42. Lalouni M, Hesser H, Bonnert M, Hedman-Lagerlof E, Serlachius E, Olen O, et al. Breaking the vicious circle of fear and avoidance in children with abdominal pain: a mediation analysis. J Psychosom Res. 2021;140:110287. https://doi.org/10.1016/j.jpsychores.2020.110287.

43. Kilpelainen $\mathrm{M}$, Terho EO, Helenius $H$, Koskenvuo M. Validation of a new questionnaire on asthma, allergic rhinitis, and conjunctivitis in young adults. Allergy. 2001;56(5):377-84. https://doi.org/10.1034/j.1398-9995.2001.0560053 77.x.

44. Bohme M, Lannero E, Wickman M, Nordvall SL, Wahlgren CF. Atopic dermatitis and concomitant disease patterns in children up to two years of age. Acta Derm Venereol. 2002;82(2):98-103. https://doi.org/10.1080/0001 5550252948112.

45. Schultz Larsen F, Diepgen T, Svensson A. The occurrence of atopic dermatitis in north Europe: an international questionnaire study. J Am Acad Dermatol. 1996;34(5 Pt 1):760-4. https://doi.org/10.1016/S0190-9622 (96) $90009-2$

46. Grize L, Gassner M, Wuthrich B, Bringolf-Isler B, Takken-Sahli K, Sennhauser $\mathrm{FH}$, et al. Trends in prevalence of asthma, allergic rhinitis and atopic dermatitis in 5-7-year old Swiss children from 1992 to 2001. Allergy. 2006; 61(5):556-62. https://doi.org/10.1111/j.1398-9995.2006.01030.x.

47. Bertelsen RJ, Carlsen KC, Carlsen KH. Rhinitis in children: co-morbidities and phenotypes. Pediatr Allergy Immunol. 2010;21(4 Pt 1):612-22. https://doi. org/10.1111/j.1399-3038.2010.01066.x.

48. Kjaer HF, Eller E, Host A, Andersen KE, Bindslev-Jensen C. The prevalence of allergic diseases in an unselected group of 6-year-old children. The DARC birth cohort study. Pediatr Allergy Immunol. 2008;19(8):737-45. https://doi. org/10.1111/j.1399-3038.2008.00733.x.

49. Lodrup Carlsen KC, Haland G, Devulapalli CS, Munthe-Kaas M, Pettersen M, Granum B, et al. Asthma in every fifth child in Oslo, Norway: a 10-year follow up of a birth cohort study. Allergy. 2006;61(4):454-60. https://doi. org/10.1111/j.1398-9995.2005.00938.x.

50. Rona RJ, Keil T, Summers C, Gislason D, Zuidmeer L, Sodergren E, et al. The prevalence of food allergy: a meta-analysis. J Allergy Clin Immunol. 2007; 120(3):638-46. https://doi.org/10.1016/j.jaci.2007.05.026

51. Helgeland H, Flagstad G, Grotta J, Vandvik PO, Kristensen H, Markestad T. Diagnosing pediatric functional abdominal pain in children (4-15 years old) according to the Rome III Criteria: results from a Norwegian prospective study. J Pediatr Gastroenterol Nutr. 2009;49(3):309-15. https://doi.org/10.1 097/MPG.0b013e31818de3ab.

52. Uusijärvi A, Olén O, Malmborg P, Eriksson M, Grimheden P, Arnell H. Combining Rome III criteria with alarm symptoms provides high specificity but low sensitivity for functional gastrointestinal disorders in children. Acta Paediatr. 2018;107(9):1635-41. https://doi.org/10.1111/apa.14297.

53. Devanarayana NM, Mettananda S, Liyanarachchi C, Nanayakkara N, Mendis $\mathrm{N}$, Perera $\mathrm{N}$, et al. Abdominal pain-predominant functional gastrointestinal diseases in children and adolescents: prevalence, symptomatology, and association with emotional stress. J Pediatr Gastroenterol Nutr. 2011;53(6): 659-65. https://doi.org/10.1097/MPG.0b013e3182296033.

54. Devanarayana NM, Adhikari C, Pannala W, Rajindrajith S. Prevalence of functional gastrointestinal diseases in a cohort of Sri Lankan adolescents: comparison between Rome II and Rome III criteria. J Trop Pediatr. 2011; 57(1):34-9. https://doi.org/10.1093/tropej/fmq039.

55. Saps M, Velasco-Benitez CA, Langshaw AH, Ramírez-Hernández CR. Prevalence of functional gastrointestinal disorders in children and 
adolescents: comparison between Rome III and Rome IV criteria. J Pediatr. 2018;199:212-6. https://doi.org/10.1016/j.jpeds.2018.03.037.

56. Schurman JV, Singh M, Singh V, Neilan N, Friesen CA. Symptoms and subtypes in pediatric functional dyspepsia: relation to mucosal inflammation and psychological functioning. J Pediatr Gastroenterol Nutr. 2010;51(3):298303. https://doi.org/10.1097/MPG.0b013e3181d1363c.

57. Walker MM, Aggarwal KR, Shim LS, Bassan M, Kalantar JS, Weltman MD, et al. Duodenal eosinophilia and early satiety in functional dyspepsia: confirmation of a positive association in an Australian cohort. J Gastroenterol Hepatol. 2014;29(3):474-9. https://doi.org/10.1111/jgh.12419.

\section{Publisher's Note}

Springer Nature remains neutral with regard to jurisdictional claims in published maps and institutional affiliations.

Ready to submit your research? Choose BMC and benefit from:

- fast, convenient online submission

- thorough peer review by experienced researchers in your field

- rapid publication on acceptance

- support for research data, including large and complex data types

- gold Open Access which fosters wider collaboration and increased citations

- maximum visibility for your research: over $100 \mathrm{M}$ website views per year

At $\mathrm{BMC}$, research is always in progress.

Learn more biomedcentral.com/submissions 